\title{
Pelatihan mikroskopis dan entomologi pada tenaga laboratorium dan entomologis lokal di Kecamatan Kokap untuk mendukung eliminasi malaria di Kabupaten Kulon Progo, DIY
}

\author{
Elsa Herdiana Murhandarwati, ${ }^{1,}{ }^{*}$ Rizqiani Amalia Kusumasari, ${ }^{1}$ Purwono, ${ }^{1}$ Kuswati, ${ }^{1}$ Sulistyawati, ${ }^{2}$ Sitti \\ Rahmah Umniyati, ${ }^{1}$ Mahardika Agus Wijayanti, ${ }^{1}$ Tri Baskoro Tunggul Satoto' \\ ${ }^{1}$ Departemen Parasitologi, Fakultas Kedokteran, Kesehatan Masyarakat dan Keperawatan, \\ Universitas Gadjah Mada, Yogyakarta, Indonesia \\ ${ }^{2}$ Departemen Ilmu Kesehatan Masyarakat, Universitas Ahmad Dahlan, Yogyakarta, Indonesia
}

Submitted: 31 Desember 2018 Revised: 20 Januari 2019 Accepted: 21 Januari 2019

\begin{abstract}
ABSTRAK Malaria merupakan masalah kesehatan masyarakat serius di Indonesia. Penyakit ini merupakan satu dari beberapa indikator yang menjadi target mulai dari millennium development goals (MDGs) pada 2015 hingga kini menjadi sustainable development goals (SDGs). Di daerah endemis malaria seperti di Kokap, Kulon Progo, Yogyakarta, kasus malaria tercatat telah menurun hingga tanpa temuan kasus pada 2000, tetapi jumlah kasus kembali meningkat pada 2011, bahkan diikuti dengan beberapa kejadian luar biasa (KLB) pada 2012. Kasus KLB yang akan terjadi diharapkan dapat dihindari apabila personel kesehatan termasuk petugas mikroskopis di puskesmas dan surveyor entomologi dilengkapi dengan pelatihan yang memadai terkait malaria. Pelatihan tersebut juga dapat digunakan sebagai penyegaran bagi petugas lama di daerah endemis malaria untuk mendukung eliminasi di wilayah Puskesmas Kokap I, Kokap II, dan di beberapa puskesmas sekitar. Pada Oktober 2013, Departemen Parasitologi, Fakultas Kedokteran, Kesehatan Masyarakat, dan Keperawatan (FK-KMK), Universitas Gadjah Mada (UGM) melaksanakan pelatihan mikroskopis dan entomologi dasar terkait malaria di wilayah kerja Puskesmas Kokap. Metode pelatihannya berupa pemberian materi dan praktek langsung di lapangan. Pelatihan yang diberikan berupa pelatihan mikroskopis malaria, pelatihan entomologi dasar, dan pemetaan perindukan vektor malaria menggunakan global positioning system (GPS). Pelatihan ini memfasilitasi petugas puskesmas untuk secara tepat mengidentifikasi spesies Plasmodium, mengidentifikasi tempat perkembangbiakan vektor lama maupun baru, serta mengetahui cara melakukan pemetaan persebaran vektor dan kasus malaria di wilayahnya. Hasil dari pelatihan menunjukkan bahwa terdapat peningkatan pengetahuan petugas puskesmas yang mengikuti pre-test dan post-test. Dari praktek lapangan, ditemukan tiga spesies yaitu Anopheles vagus, Anopheles annularis, dan Anopheles maculatus. Pada pembedahan nyamuk dewasa yang tertangkap, ditemukan nyamuk nulliparous dan parous berdasarkan hasil pengamatan tracheole skeins ovariumnya. Tidak ditemukan adanya ookista pada lambung dan sporozoite pada kelenjar ludah saat pembedahan nyamuk dewasa. Pelatihan seperti ini diharapkan dapat diterapkan di area lainnya di masa mendatang.
\end{abstract}

KATA KUNCI entomologi; kejadian luar biasa; malaria; mikroskopis; pemetaan GPS

ABSTRACT Malaria is a serious public health problem in Indonesia. This disease is one of several indicators that have been targeted from the Millennium Development Goals (MDGs) 2015 to become Sustainable Development Goals (SDGs). In malaria-endemic areas such as in Kokap, Kulon Progo, Yogyakarta, reported

\footnotetext{
*Corresponding author: Elsa Herdiana Murhandarwati

Departemen Parasitologi, Fakultas Kedokteran, Kesehatan Masyarakat, dan Keperawatan, Universitas Gadjah Mada, JI. Farmako, Sekip Utara, Yogyakarta 55281, Indonesia

E-mail: elsa.herdiana@ugm.ac.id
} 
malaria cases declined in 2000 with no case, but increased in 2011 following by some outbreaks in 2012. Future outbreaks could be avoided when health personnel including Primary Health Care (PHC) microscopists and entomologist surveyors were equipped with adequate trainings related to malaria. This training also be used for refreshment for existing personnel to support elimination at the Kokap I, Kokap II, and several nearby PHCs. In October 2013, the Department of Parasitology, Faculty of Medicine, Public Health, and Nursing, Universitas Gadjah Mada (UGM) carried out microscopic training and basic entomology related to malaria in the working area of PHC in Kokap. Training methods were giving material and direct activities in the field. The training provided basic entomology training, malaria microscopic training, and malaria vector mapping using a global positioning system (GPS). The training facilitated PHC personnel to do correct identification of Plasmodium species, identification of old and new vector breeding sites, and found out how to map vector distribution and malaria cases in their area. The results showed that there was an increase in knowledge from PHC personnel who participated in the pre-test and post-test. From field activity, three adult mosquitoes species were found i.e. Anopheles vagus, Anopheles annularis, and Anopheles maculatus. Nulliparous and parous mosquitoes from adult mosquito based on the examination of their tracheole skeins of ovarium were found from the collected mosquitoes although oocyst in midgut and sporozoite in salivary gland were not found during adult mosquito surgical. Similar trainings were expected to be applied in other similar areas in the future.

KEYWORDS entomology; outbreak; malaria; microscopic; GPS mapping

\section{Pendahuluan}

Malaria merupakan salah satu masalah kesehatan masyarakat yang dapat menyebabkan kesakitan dan kematian. Transmisi malaria di Indonesia berlangsung sepanjang tahun. Kasus malaria di Kabupaten Kulon Progo secara umum menunjukkan penurunan yang dapat dilihat dari nilai annual parasite incidence (API) 85,9\%o pada tahun 2000 menjadi $0,2 \%$ pada tahun 2007. Pada tahun 2011, API malaria di Indonesia sudah mencapai $1,96 \%$ o walaupun di beberapa tempat masih sering ditemui adanya peningkatan jumlah kasus maupun kejadian luar biasa (KLB). Salah satu contoh KLB malaria yang terjadi di Provinsi Daerah Istimewa Yogyakarta (DIY) yaitu KLB pada tahun 2012 di kecamatan yang berada di Pegunungan Menoreh, Kecamatan Kokap, Kulon Progo. ${ }^{1}$

Daerah high case incident $(\mathrm{HCl})$ malaria di Indonesia mengalami penurunan. Pada tahun 2006 sudah tidak ditemukan adanya kasus malaria, tetapi pada tahun 2009 peningkatan penyebaran malaria di Kulon Progo mulai terlihat. ${ }^{1}$ Walaupun pada tahun 2010 nilai API hanya sebesar 0,03\%, masih ada satu desa dengan status middle case incident (MCl) dan terdapat 13 desa dengan status low case incident (LCI). ${ }^{2}$ Hingga November 2011, total kasus malaria telah mencapai 92 kasus atau meningkat sebesar $65,2 \%$ sejak tahun $2010 .^{3}$

Penurunan atau menghilangnya kasus malaria antara tahun 2007 - 2009 menyebabkan kurangnya kewaspadaan terhadap malaria yang diperberat dengan hilangnya beberapa program pengendalian malaria, misalnya dengan pengurangan jumlah juru malaria desa (JMD) ${ }^{4}$ atau keterbatasan penyelenggaraan penyegaran bagi tenaga mikroskopis malaria maupun tenaga entomologis terutama pada daerah dengan dugaan malaria telah hilang. Mengingat malaria merupakan penyakit yang kompleks dan disebabkan oleh banyak faktor maka untuk menghilangkan malaria harus dilakukan upaya integrasi semua komponen terkait dan upaya pemberantasan malaria harus dimasukkan sebagai bagian integral dari pembangunan nasional. ${ }^{5}$ Pusat kesehatan masyarakat (puskesmas) merupakan lembaga yang berada di garis depan dalam deteksi dini dan pencegahan serta layanan pertama dalam menghadapi wabah atau KLB. Puskesmas juga merupakan institusi rujukan resmi untuk layanan kesehatan dasar seperti pos kesehatan desa 
(poskesdes) yang berada di bawah tanggung jawab bidan. ${ }^{6} \mathrm{KLB}$ berkontribusi meningkatkan mortalitas yang bermakna secara epidemiologis di suatu desa atau kecamatan pada waktu tertentu. ${ }^{6}$ Aktivitas deteksi dini adalah kesadaran akan terjadinya KLB dengan mengidentifikasi potensi kasus KLB, memantau daerah setempat untuk penyakit yang berpotensi KLB, serta melakukan penyelidikan dugaan KLB. ${ }^{7}$ Kasus KLB harus diselidiki dengan metode epidemiologis, mulai dari mengetahui bagaimana penyebarannya hingga cara untuk mengatasinya.

Menurut Keputusan Menteri Kesehatan tahun 2009, peningkatan sumber daya manusia (SDM) dalam bentuk pelatihan bagi petugas kesehatan di puskesmas (dan rumah sakit) juga merupakan bagian penting dari awal eradikasi hingga tahap eliminasi. Pelatihan, penyegaran, dan pemberian motivasi masih diperlukan di daerah-daerah yang telah memasuki fase eliminasi karena fase pemeliharaan eliminasi malaria sangat penting. ${ }^{5}$ Untukmemberikan data yang akurat, pemberdayaan ahli entomologi dengan keterampilan pemetaan menggunakan sistem informasi geografi (SIG) akan membantu lembaga terkait dalam perencanaan dan implementasi intervensi vektor. Dengan demikian, risiko terjadinya KLB diharapkan dapat diminimalisir atau bahkan dicegah. ${ }^{7}$

Tujuan kegiatan ini adalah untuk memberdayakan personel mikroskopis dan entomologi di Puskesmas Kokap dan daerah sekitarnya dengan pelatihan yang diharapkan dapat menghasilkan petugas mikroskopis yang memiliki akurasi tinggi dalam mendiagnosis Plasmodium pada apusan darah konvensional, ahli entomologi yang andal dan memiliki keterampilan untuk mengumpulkan larva dan nyamuk Anopheles spp. dewasa, mampu mengidentifikasi tempat perkembangbiakan yang potensial, mengetahui perilaku nyamuk serta mengenali spesies malaria yang berpotensi menular, serta petugas lapangan yang dapat memetakan hasil mikroskopis dan entomologis dengan pendekatan SIG. ${ }^{8}$

\section{Metode}

Penelitian ini telah mendapatkan izin etik dari Komisi Etik Fakultas Kedokteran, Kesehatan Masyarakat, Keperawatan (FK-KMK), Universitas Gadjah Mada (UGM) dengan nomor KE/FK/0514/ $E C / 2019$. Penelitian ini menggunakan salah satu strategi dalam mendukung eliminasi malaria yaitu meningkatkan kompetensi dari segi SDM yang berada di wilayah kerja Puskesmas Kokap I, Kokap II, dan beberapa wilayah kerja puskesmas lainnya yang berada di Kabupaten Kulon Progo. Metode yang digunakan adalah melakukan pemberdayaan tenaga mikroskopis laboratorium dan tenaga entomologi puskesmas. Pemberdayaan untuk meningkatkan kompetensi tenaga puskesmas dilakukan dengan pemberian pelatihan dan pendampingan, serta pengujian untuk mengukur kemampuan sebelum dan setelah pelatihan. Pelatihan dan pendampingan dilakukan oleh 5 dosen dan 2 teknisi dari Departemen Parasitologi, FK-KMK, UGM serta 1 dosen dari Departemen IImu Kesehatan Masyarakat, Universitas Ahmad Dahlan, Yogyakarta. Pelatihan dilakukan selama bulan Oktober 2013 dalam 5 jenis pelatihan. Jenis pelatihan dan pendampingan yang dilakukan adalah:

a. Pelatihan mikroskopis yang meliputi pemeriksaan mikroskopis terhadap sediaan apusan darah tipis dan tebal berbagai stadium Plasmodium falciparum, Plasmodium vivax, Plasmodium malariae, dan Plasmodium ovale. Pelatihan dilakukan di Departemen Parasitologi, FK-KMK, UGM.

b. Pelatihan entomologi dasar yang meliputi identifikasi stadium telur, larva, pupa, dan imago nyamuk Anopheles, Aedes, Culex, dan Mansonia secara mikroskopis dan visual. Petugas juga dilatih untuk mengenali vektor malaria di wilayah puskesmas Kokap II dengan survei lapangan lalu dibimbing mengidentifikasi Anopheles dengan panduan identifikasi nyamuk dari Kementerian Kesehatan yang telah diperbarui oleh Balai Besar Penelitian dan 
Pengembangan Vektor dan Reservoir Penyakit (B2P2VRP) Salatiga. Pelatihan dilakukan di Departemen Parasitologi, FK-KMK, UGM.

c. Praktik lapangan (field trip) untuk mencari tempat perkembangbiakan larva, pencidukan larva, penghitungan larva pada sore hari, penangkapan Anopheles dewasa menggunakan umpan di dalam dan di luar rumah, serta di sekitar kandang ternak di Desa Soko di wilayah Puskesmas Kokap II.

d. Identifikasi spesies yang meliputi bedah kelenjar saliva, bedah abdomen, dan bedah ovarium. Tenaga entomologis dilatih mengidentifikasi keberadaan sporozoit dengan membedah kelenjar saliva pada toraks nyamuk Anopheles, membedah abdomen untuk mengidentifikasi keberadaan oosista pada lambung nyamuk, dan membedah ovarium untuk melihat kondisi ovarium (nulliparous atau parous) berdasarkan pengamatan tracheole skein ovariumnya menggunakan Optilab. Pelatihan ini diselenggarakan di kantor Dinas Kesehatan Kulon Progo.

e. Pelatihan pemetaan menggunakan SIG. Pelatihan dimulai dengan pembagian dan panduan penggunaan global positioning system (GPS) dan dilanjutkan praktik di lapangan. Pelatihan dilakukan di lingkungan Departemen Parasitologi, FK-KMK, UGM. Pelatihan pemetaan diberikan dalam bentuk teori dasar, contoh dan aplikasi praktis penggunaan GPS dan perangkat lunak terkait. Pada pelatihan tersebut, disajikan juga perbedaan dan kelebihan penyajian data secara visual dengan peta dibandingkan dengan penyajian data deskriptif, tabular, dan diagram. Tahap paling penting dari pelatihan ini adalah bagaimana membaca peta dan hasil analisa SIG sehingga dapat digunakan untuk penentuan arah kebijakan. Materi pelatihan yang diberikan dalam pemetaan penyakit dengan SIG menggunakan GPS meliputi pelacakan (membuat rute), menandai objek, menyimpan data yang telah dibuat, memindahkan data dari GPS ke komputer dan perangkat lunak, serta memvisualisasikan data dan hasil untuk membuat analisis.

Seluruh peserta diminta untuk mengerjakan pre-test berupa soal yang berkaitan dengan tanda spesifik dari spesies Plasmodium beserta stadiumnya. Soal pre-test diberikan sebelum pemberian materi dan selanjutnya diberikan posttest di akhir pelatihan dengan soal yang sama untuk melihat pengetahuan awal dan setelah diberikan materi. Hasil pelatihan pre-test dan posttest diuji secara statistik menggunakan SPSS versi 22.0 dengan metode uji Wilcoxon. Materi dasar yang diberikan sebelum pelaksanaan pelatihan adalah informasi detail mengenai penyakit malaria, sejarah ditemukannya malaria, penyebab penyakit malaria, akibat yang ditimbulkan dari penyakit malaria, kelompok yang berisiko tinggi tertular malaria, dan distribusi daerah endemis malaria di Indonesia terutama di Kabupaten Kulon Progo. Peserta juga dibagikan buku panduan singkat entomologi malaria dan pemeriksaan mikroskopis malaria serta alat GPS sebanyak 2 buah yang diterima oleh petugas penanggungjawab program malaria di Puskesmas Kokap I dan Kokap II

\section{Hasil}

\subsection{Pelatihan mikroskopis malaria}

Pelatihan mikroskopismalaria diikutioleh13 peserta, yaitu masing-masing 1 orang dari Puskesmas Kokap I, Puskesmas Girimulyo I, Puskesmas Girimulyo II, Puskesmas Samigaluh I, Puskesmas Samigaluh II, Puskesmas Kalibawang, Puskesmas Temon I, Puskesmas Pengasih I, Puskesmas Pengasih II, serta 2 orang dari Puskesmas Kokap II. Dinas Kesehatan Kabupaten Kulon Progo juga diundang dan 2 orang perwakilannya datang mengikuti pelatihan. Nilai pre-test dan post-test peserta pelatihan mikroskopis disajikan dalam Tabel 1. Dari hasil uji statistik Wilcoxon didapatkan bahwa 13 subjek pengetahuannya meningkat $(p=0,001)$.

\subsection{Pelatihan entomologi dasar}

Pelatihan entomologi dasar diikuti oleh 16 orang peserta yang berasal dari Puskesmas Kokap I (3 orang), Puskesmas Kokap II (4 orang), Puskesmas 
Tabel 1. Hasil nilai pre-test dan post-test pelatihan mikroskopis

Median (minimum - maksimum)

p

Nilai pre-test $(\mathrm{n}=13)$

$68(0-84)$

0,001

Nilai post-test $(n=13)$

$92(64-100)$

Tabel 2. Hasil nilai pre-test dan post-test peserta pelatihan entomologi dasar

\begin{tabular}{lcc}
\hline & Median (minimum - maksimum) & $\boldsymbol{p}$ \\
\hline Nilai pre-test $(\mathrm{n}=16)$ & $3(0-9)$ & 0,001 \\
Nilai post-test $(\mathrm{n}=16)$ & $10(6-10)$ & \\
\hline
\end{tabular}

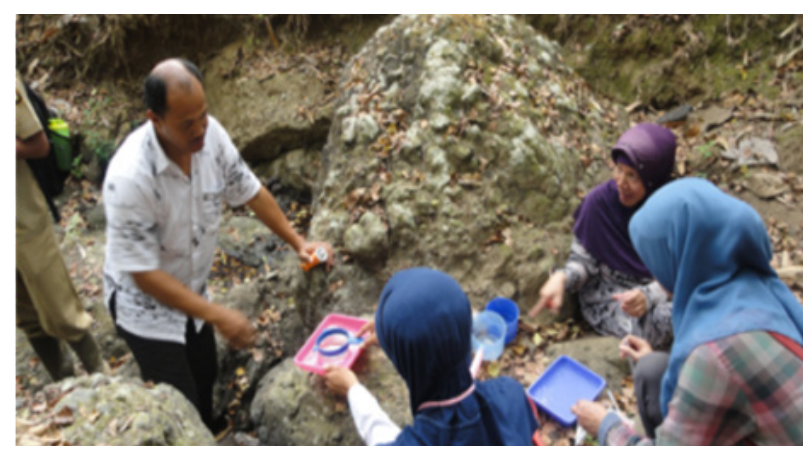

(a)

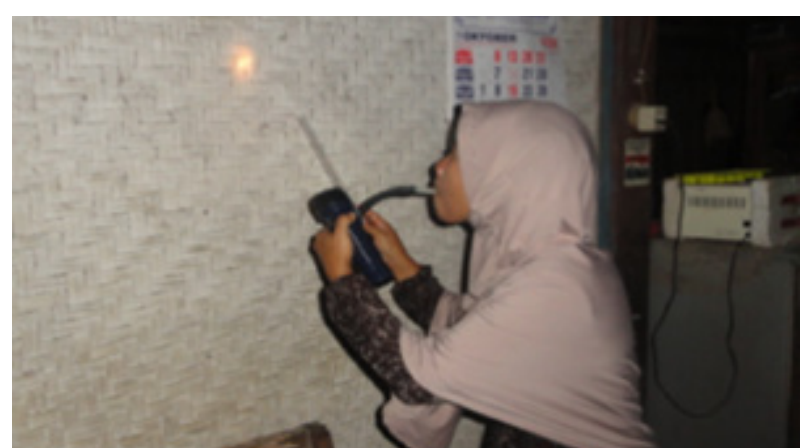

(b)

Gambar 1. (a) Pencarian tempat perkembangbiakan larva nyamuk di lapangan. (b) Proses koleksi Anopheles dewasa secara indoor di malam hari.

Girimulyo I (1 orang), Puskesmas Girimulyo II (1 orang), Puskesmas Samigaluh I (1 orang), Puskesmas Samigaluh II (1 orang), Puskesmas Kalibawang (1 orang), dan Puskesmas Pengasih II (1 orang). Dinas Kesehatan Kabupaten Kulon Progo juga diundang dan 3 orang perwakilannya datang mengikuti pelatihan. Hasil pre-test dan post-test peserta pelatihan entomologi ditunjukkan pada Tabel 2 . Lima belas subjek pengetahuannya meningkat dan 1 subjek pengetahuannya menurun, namun secara statistik terjadi peningkatan pengetahuan $(p=$ 0,001 ).

\subsection{Praktik lapangan (field trip)}

Praktik lapangan bagi tenaga entomologis dilakukan di desa Soko yang berada di wilayah Kokap II dan diikuti oleh 16 peserta yang sama dengan pelatihan entomologi dasar sebelumnya. Kegiatan praktik lapangan ini berupa pencarian tempat perkembangbiakan larva Anopheles, pencidukan larva nyamuk Anopheles, penghitungan larva Anopheles yang didapatkan, serta penangkapan nyamuk Anopheles dewasa pada sore hingga malam hari (Gambar 1).

\subsection{Identifikasi spesies dan bedah nyamuk Anopheles}

Identifikasi spesies nyamuk Anopheles dilakukan di Dinas Kesehatan Kabupaten Kulon Progo dengan didampingi oleh teknisi ahli dari Departemen Parasitologi, FK-KMK, UGM. Spesies Anopheles hasil penangkapan nyamuk dewasa saat field trip diidentifikasi. Spesies nyamuk Anopheles yang berhasil diidentifikasi adalah Anopheles vagus, Anopheles annularis, dan Anopheles maculatus.

Proses bedah kelenjar ludah dan bedah ovarium dilakukan oleh setiap peserta didampingi oleh teknisi dari Laboratorium Parasitologi, 


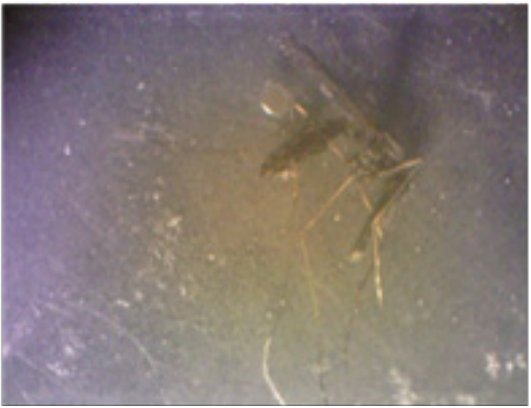

(a)

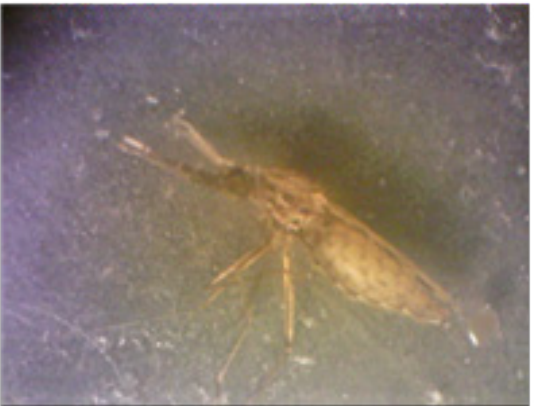

(b)

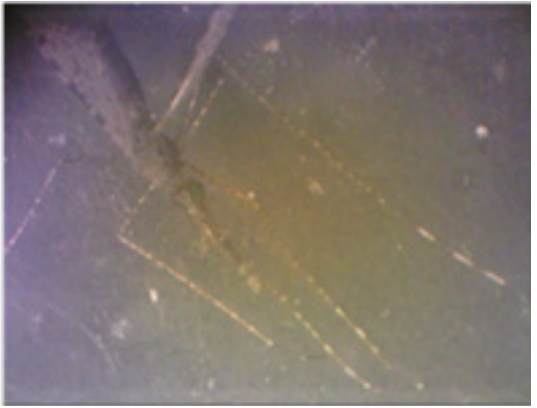

(c)

Gambar 2. Spesies nyamuk yang berhasil diidentifikasi dari hasil penangkapan di lapangan yaitu (a) An. annularis, (b) An. vagus, dan (c) An. maculatus.

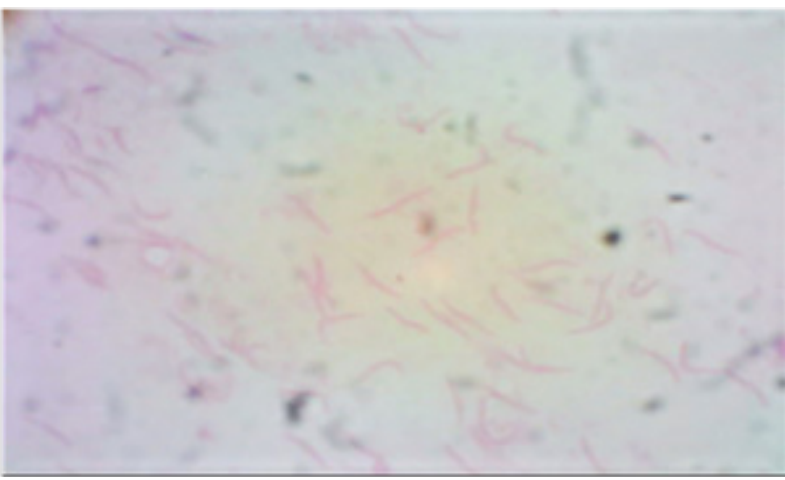

(a)

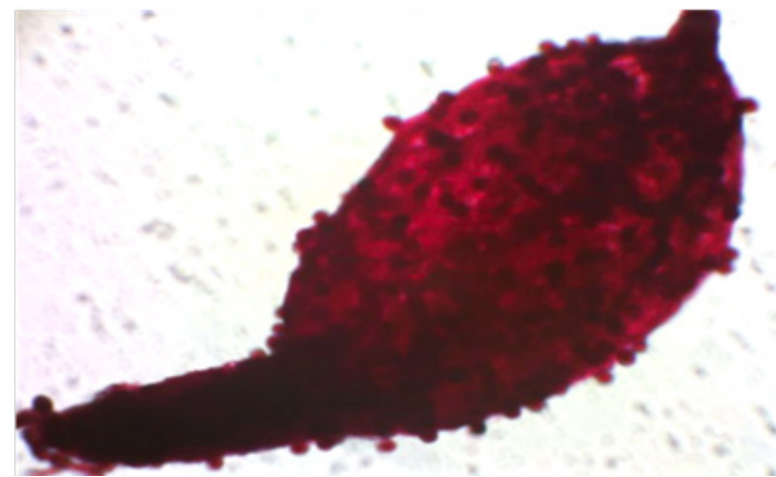

(b)

Gambar 3. Hasil pemotretan preparat koleksi Departemen Parasitologi, FK-KMK, UGM yang dilakukan pada saat pelatihan di kantor Dinas Kesehatan Kulon Progo. (a) Sporozoit yang ditemukan pada kelenjar ludah Anopheles pada pembesaran 1000x. (b) Ookista pada perut Anopheles pada pembesaran 400x.

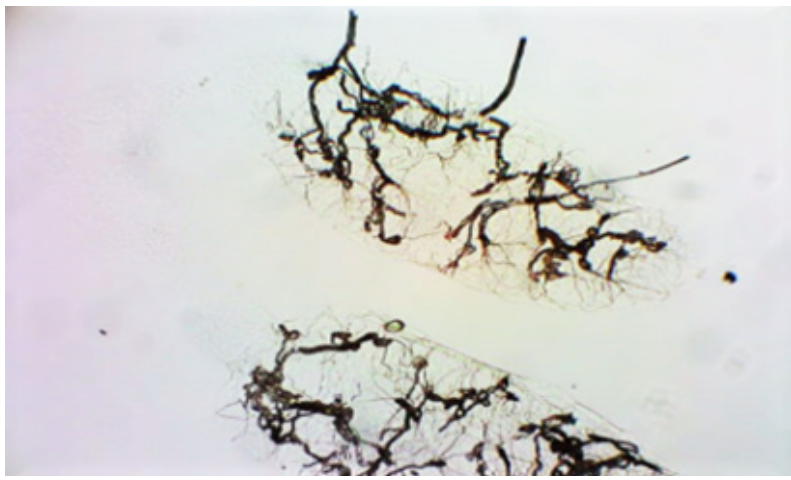

(a)

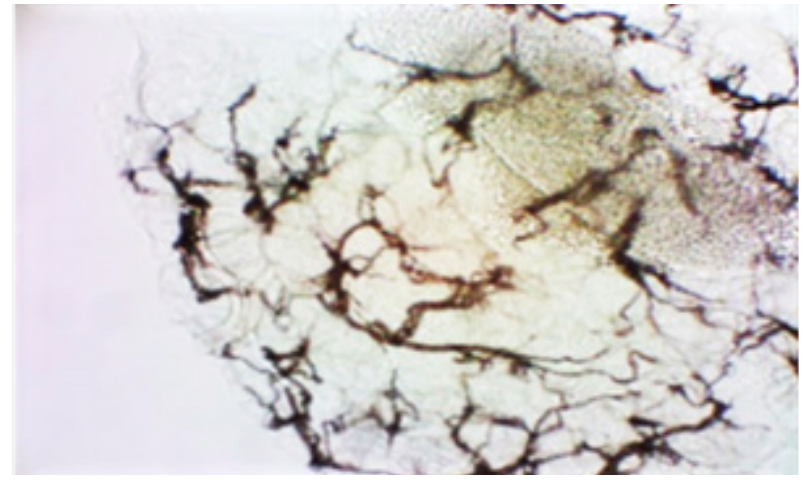

(b)

Gambar 4. Bentuk ovarium Anopheles pada pembesaran 100x. (a) Nulliparous. (b) Parous.

FK-KMK, UGM. Pada pembedahan kelenjar ludah tidak ditemukan sporozoit Plasmodium (Gambar 3(a)) dan pada pembedahan abdomen juga tidak ditemukan ookista pada lambung (Gambar 3(b)), sedangkan pada pembedahan ovarium ditemukan bentuk nulliparous dan parous seperti pada Gambar 4.

\subsection{Pelatihan pemetaan dengan SIG}

Pelatihan pemetaan menggunakan SIG diikuti oleh hanya 6 peserta dengan harapan pelatihan dapat berjalan lebih intensif bagi petugas yang lebih mengerti daerah atau wilayahnya secara keseluruhan. Peserta berasal dari perwakilan Dinas Kesehatan Kabupaten Kulon Progo serta penanggungjawab program eliminasi malaria 
di Puskesmas Kokap I dan Puskesmas Kokap II, masing-masing sebanyak 2 orang. Materi pelatihan pemetaan ini adalah teori dasar pemetaan secara geografi dan komparasi penyajian data dalam bidang kesehatan menggunakan SIG dengan alat bantu GPS yang kemudian diolah menggunakan perangkat lunak ArcView 3.3. Pelatihan yang diberikan meliputi proses pengambilan data koordinat dengan menggunakan GPS, memindahkan data GPS ke dalam komputer, serta memetakan data dengen SIG. Luaran utama pelatihan ini adalah peta, baik dalam bentuk soft file maupun print out.

\section{Pembahasan}

Menurut Keputusan Menteri Kesehatan tahun 2009, peningkatan sumber daya manusia (SDM) dengan pelatihan bagi petugas kesehatan di puskesmas (dan rumah sakit) merupakan bagian penting dari awal tahap eradikasi hingga tahap eliminasi. Pelatihan, penyegaran, dan pemberian motivasi masih diperlukan di daerah-daerah yang telah masuk fase eliminasi karena fase pemeliharaan eliminasi malaria sangat penting. ${ }^{5}$ Untuk memberikan data yang akurat, pemberdayaan ahli entomologi dengan keterampilan pemetaan SIG akan membantu lembaga terkait dalam perencanaan dan implementasi intervensi vektor. Dengan demikian, risiko terjadinya KLB diharapkan dapat diminimalisir atau bahkan dapat dicegah. ${ }^{7}$

Peningkatan dan pengembangan SDM di bidang kesehatan adalah kegiatan yang harus dilakukan oleh suatu instansi kesehatan atau yang bekerja sama dengan instansi tersebut. Kegiatan tersebut untuk meningkatkan dan mengembangkan SDM dilakukan dengan cara memberikan pendidikan dan pelatihan di bidang kesehatan. $^{9}$ Kegiatan tersebut dilakukan agar pengetahuan, kemampuan, dan keterampilan SDM sesuai dengan tuntutan pekerjaan yang menjadi tanggungjawabnya. Pelatihan diharapkan dapat memperbaiki dan mengatasi kekurangan yang ada sehingga kinerja mereka menjadi lebih baik. Selain itu, pelatihan perlu dilakukan secara berkala dan berkelanjutan dengan mengikuti perkembangan ilmu, teknologi, lingkungan, dan keadaan sekitar agar keterampilan dan ilmu SDM tetap relevan. ${ }^{10}$

\subsection{Pelatihan mikroskopis malaria}

Pelatihan mikroskopis masih perlu diberikan kepada petugas yang baru maupun yang lama. Hal ini dilakukan berdasarkan fakta-fakta di beberapa daerah endemis malaria bahwa di mana tingkat kesalahan pemeriksaan sediaan apusan darah di puskesmas masih tinggi, kualitas sediaan apusan darah belum terstandarisasi, serta petugas laboratorium dan juru malaria desa (JMD) tidak semuanya terbiasa membuat sediaan apusan darah untuk pemeriksaan malaria. Tingginya tingkat kesalahan dalam membaca dan mengidentifikasi sediaan malaria masih umum ditemukan di puskesmas-puskesmas di Indonesia. Salah satu contohnya adalah puskesmas di Belu, Nusa Tenggara Timur. Di Belu, tingkat kesalahan dalam mengidentifikasi spesies Plasmodium tinggi, dengan rentang $20,0 \%$ hingga $80,0 \%{ }^{11}$

Hasil pelatihan menunjukkan bahwa 13 orang peserta mengalami peningkatan pengetahuan setelah diberikan pelatihan. Tabel 1 menunjukkan bahwa terdapat perbedaan nilai tes yang bermakna antara sebelum dan sesudah diberikan pelatihan. Hal ini menunjukkan bahwa pelatihan dan penyegaran materi mikroskopis masih diperlukan bagi tenaga mikroskopis puskesmas terutama di daerah endemis malaria agar pengetahuannya meningkat dan kemampuannya terus terjaga. Setelah diberikan pelatihan, para peserta diharapkan mampu membedakan jenis spesies dan stadium Plasmodium yang dijumpai di wilayahnya.

Hingga sekarang, diagnosis malaria ditentukan berdasarkan gejala klinis yang kemudian dikonfirmasi dengan pemeriksaan apusan darah secara mikroskopis. Dalam pemeriksaan mikroskopis dijumpai banyak kendala, yaitu rentang waktu yang lama untuk mendapatkan hasil, terbatasnya jumlah petugas mikroskopis yang terlatih, serta kesamaan hasil pemeriksaan antar pemeriksa yang masih rendah (nilai kesepakatan Kappa < 0,61). ${ }^{12}$ Kemampuan untuk mengidentifikasi parasit malaria dengan tepat secara mikroskopis sangat diperlukan, terutama dalam penegakan diagnosis malaria dan pemantauan pengobatan anti-malaria. Selain itu, identifikasi Plasmodium diperlukan 
dalam penapisan malaria, pengawasan migrasi malaria, penyelidikan epidemiologi, dan survei darah massal.

Kesamaan hasil pemeriksaan mikroskopis malaria yang dilakukan oleh petugas laboratorium di daerah endemis malaria di Indonesia bervariasi antara < 50,0\% hingga 95,0\%. ${ }^{13}$ Pada beberapa daerah endemis malaria di Indonesia, petugas kesehatan terlibat dalam pembuatan sediaan darah tebal malaria yang dapat digunakan untuk menentukan keberadaan Plasmodium dalam darah. Di Indonesia, sudah ada mekanisme untuk pemeriksaan silang pada apusan darah secara bertahap sesuai dengan tingkat administrasi, mulai tingkat fasilitas kesehatan primer hingga tingkat provinsi. Namun, pemeriksaan silang tersebut tidak berjalan dengan baik karena keterbatasan dana dan sumber daya manusia. ${ }^{14}$

Dalam pembuatan apusan darah tipis, tidak semua petugas kesehatan di puskesmas mampu membuat sediaan darah dan mengidentifikasi spesies dengan baik dan benar. Ketidaktepatan dalam identifikasi spesies dapat mengakibatkan perawatan yang tidak tepat sehingga menyebabkan penularan yang berkelanjutan, memperburuk penyakit, hingga kematian. ${ }^{12}$ Masalah lain yang dapat terjadi adalah resistensi Plasmodium terhadap obat malaria yang muncul sebagai akibat pengobatan yang tidak sesuai untuk spesies Plasmodium yang menginfeksi. Oleh karena itu, keterampilan membuat sediaan apusan darah tebal dan tipis, serta kemampuan mengidentifikasi keberadaan dan jenis Plasmodium merupakan fondasi yang penting bagi program eliminasi malaria. Keterampilan mengidentifikasi bentuk Plasmodium pada setiap fase hidupnya juga penting, terutama gametosit yang terdapat dalam darah karena pada fase gametosit pasien tidak menunjukkan gejala klinis.

\subsection{Pelatihan entomologi dasar}

Pelatihan entomologi diperlukan untuk petugas entomologi puskesmas. Pelatihan tersebut memudahkan ahli entomologi saat melaksanakan survei entomologi bersama dengan kepala program malaria dalam rangka memantau vektor secara longitudinal dan berkesinambungan di wilayah administratif, misalnya di wilayah kerja Puskesmas Kokap I dan Kokap II, Kulon Progo, DIY.

Hasil pelatihan petugas entomologi ini menunjukkan bahwa 15 orang peserta dari 16 peserta mengalami peningkatan pengetahuan setelah diberikan pelatihan yang ditunjukkan dengan peningkatan nilai post-test dibandingkan dengan nilai pre-test $(p=0,001)$. Hal ini menunjukkan bahwa pelatihan dan penyegaran materi entomologi diperlukan dan penting untuk dilakukan bagi tenaga puskesmas terutama yang bekerja di daerah endemis malaria. Pada pelatihan ini, mereka diharapkan dapat membedakan spesies nyamuk secara makroskopis dan mikroskopis dengan benar.

Data entomologi yang dapat dikumpulkan dari lapangan disebut dengan bionomik nyamuk. Bionomik nyamuk berkaitan dengan usia, perkembangbiakan, populasi, distribusi, perilaku nyamuk, serta fluktuasi musiman. Bionomik nyamuk juga dapat dipengaruhi oleh faktor-faktor lain misalnya faktor lingkungan fisik, kimia, dan biologis. ${ }^{15}$

Nyamuk Anopheles adalah nyamuk nokturnal dan memiliki kebiasaan menggigit, menghisap darah, dan meletakkan telur (oviposition) pada sore hari atau dini hari. Data kepadatan nyamuk juga penting untuk diteliti dalam survei entomologi. Kepadatan dapat diukur dengan menghitung nilai man biting rate (MBR), man hour density (MHD), dan kepadatan nyamuk di setiap rumah. ${ }^{16}$ Setiap spesies Anopheles memiliki kebiasaan menggigit masing-masing. Ada spesies yang gemar menggigit di luar ruangan yang disebut exophagic, atau di dalam rumah yang disebut endophagic. Ada spesies Anopheles yang gemar beristirahat di rumah yang disebut endophilic, atau di luar rumah yang disebut exophilic. Selain itu, ada juga spesies yang menyukai darah manusia sebagai sumber makanan mereka yang disebut antropophilic, atau darah binatang yang disebut zoophilic, atau keduanya. ${ }^{17}$ Data bionomik nyamuk di setiap daerah penting karena setiap daerah memiliki jenis Anopheles yang berbeda. Data bionomik Anopheles dapat digunakan sebagai referensi untuk menentukan strategi untuk mengendalikan penyakit. ${ }^{18}$

Jika nyamuk vektor terbukti endophagic 
dan endophilic, pemasangan kawat di ventilasi menjadi penting untuk mencegah nyamuk vektor malaria masuk ke dalam rumah. Pada kondisi ini, pemilihan metode penyemprotan residu insektisida (insecticidal residual spraying/IRS) tepat untuk memperpendek usia nyamuk. Jika nyamuk exophagic dan exophilic, jamban harus berada di dalam rumah dan kegiatan di luar pada malam hari harus dihindari. Jika nyamuk bersifat antropophilic dan zoophilic maka keberadaan ternak harus berada jauh dari rumah karena ternak dapat menjadi hewan penghalang yang menyebabkan nyamuk menghisap darah hewan dan tidak mengisap darah manusia.

\subsection{Praktik lapangan (field trip), identifikasi spesies dan pembedahan spesies nyamuk Anopheles}

Anopheles disebut sebagai vektor malaria jika memenuhi sejumlah persyaratan, yaitu kontak dengan manusia yang cukup, spesies dominan, populasi nyamuk berumur panjang, dan di tempat lain terbukti memiliki kemampuan menularkan malaria. ${ }^{19}$ Nyamuk Anopheles sebagai vektor malaria penting untuk dipelajari dan diperhatikan terutama dalam mengendalikan penularan malaria. Agar dapat mengenali vektor, pengetahuan dan keterampilan terkait identifikasi tempat berkembang biak nyamuk (genangan air tawar, payau, dan asin, misalnya rawa, muara, kolam ikan atau udang, saluran irigasi, sawah, dan mata air dengan aliran lambat), koleksi larva nyamuk, dan koleksi nyamuk dewasa sangat penting dimiliki oleh petugas.

Pelatihan entomologi untuk tenaga kesehatan puskesmas sangat penting. Pelatihan tersebut dapat digunakan sebagai upaya penyegaran bagi yang berpengalaman dan meningkatkan kemampuan bagi tenaga kesehatan baru dalam entomologi. Praktik di lapangan juga membutuhkan landasan pengetahuan dalam bentuk materi dan teori yang kuat sebelumnya agar praktik di lapangan berjalan lebih baik.

Pada pelatihan ini, pengambilan sampel air yang mengandung larva dilakukan siang hari dan penangkapan nyamuk dewasa dilakukan pada sore hingga malam hari. Nyamuk dewasa ditangkap sekitar satu jam, yaitu 40 menit untuk penangkapan di dalam atau di luar rumah, 10 menit untuk menangkap nyamuk yang mendarat atau dalam posisi istirahat (pada dinding atau semak-semak), dan 10 menit untuk pelabelan sampel nyamuk di gelas kertas. Metode penangkapan yang digunakan ini berasal dari World Health Organization (WHO). Nyamuk dewasa yang ditangkap bukan hanya Anopheles, tetapi semua nyamuk dewasa yang ditemukan sehingga dapat dilihat adanya variasi spesies nyamuk di wilayah tersebut. Semua nyamuk dewasa kemudian dipisahkan berdasarkan waktu penangkapan dan metode penangkapan (di dalam atau di luar ruangan). ${ }^{16}$ Pengetahuan tentang alat yang digunakan untuk menangkap nyamuk seperti perangkap cahaya dan aspirator juga penting diketahui dan diterapkan pada praktik lapangan ini.

Bedah kelenjar ludah dilakukan untuk mengonfirmasi apakah Anopheles yang ditangkap merupakan vektor malaria atau bukan. Jika ditemukan sporozoit di dalamnya maka spesies nyamuktersebut dinyatakan sebagaivektorsehingga di masa mendatang perlu upaya pencegahan untuk mengendalikan spesies tersebut.

Bedah ovarium dilakukan dengan cara menarik ujung abdomen nyamuk Anopheles sehingga terlihat ovariumnya keluar. Setelah itu dapat diidentifikasi apakah nyamuk tersebut parous (sudah pernah bertelur/berusia tua) atau nulliparous (belum pernah bertelur/berusia muda). Jika di daerah endemis malaria lebih banyak ditemukan nyamuk parous (lebih dari 70,0\%) maka di daerah tersebut populasi nyamuk didominasi oleh nyamuk infektif yang siap menularkan parasit malaria.

Hal lain yang sangat penting untuk dikuasai oleh ahli entomologi adalah cara menemukan tempat perkembangbiakan larva, cara mengambil larva, cara menghitung kepadatan larva, dan cara memberi kode label sesuai tempat pengambilan sampel. Larva Anopheles yang tertangkap harus dipelihara di dalam insektarium sampai menjadi dewasa. Nyamuk betina dewasa yang berusia 3 5 hari dapat digunakan sebagai subjek penelitian untuk menentukan status kerentanan terhadap insektisida dalam program pengendalian vektor malaria dengan metode yang telah distandarisasi oleh WHO dan Center for Disease Control and Prevention (CDC). Nyamuk tersebut juga dapat 
digunakan sebagai subjek penelitian untuk menentukan status kompetensi nyamuk terhadap Plasmodium falciparum dan Plasmodium vivax dengan memberikan darah nyamuk pada pembawa gametosit per oral menggunakan membran pakan (membrane-feeding). Selama $4-8$ hari setelah pemberian darah dengan gametosit positif, perut nyamuk diisolasi untuk membuktikan keberadaan ookista. Setelah 10 - 18 hari pemberian makan darah, kelenjar ludah nyamuk diisolasi untuk membuktikan keberadaan sporozoit di kelenjar ludah.

Upaya pengendalian vektor adalah salah satu komponen penting dalam strategi pengendalian malaria. Namun demikian, tidak harus semua jenis Anopheles di daerah endemis diberantas. ${ }^{20}$ Oleh karena itu, pengetahuan tentang berbagai jenis vektor malaria merupakan hal yang sangat penting untuk diketahui oleh tenaga entomologis di setiap puskesmas. Jenis-jenis vektor malaria dapat berbeda antardaerah tergantung dari spesies Anopheles yang dijumpai di masing-masing daerah.

\subsection{Peningkatan aktivitas pemetaan dengan SIG}

Pemetaan merupakan langkah penting dalam menangani penyakit dengan tujuan untuk menggambarkan distribusi kasus penyakit secara spasial dan pada tahap lebih lanjut untuk mencari keterkaitan antara penyakit dan lingkungan. Suatu penelitian menyatakan bahwa pola geografis penyakit dapat dijelaskan secara epidemiologi berdasarkan waktu, orang, dan tempat dengan memetakan penyakit tersebut. Penelitian lain menyebutkan bahwa peta merupakan solusi untuk misteri medis. ${ }^{21}$ Seiring dengan perkembangan teknologi, terutama komputer, pembuatan peta yang dahulu dilakukan secara manual, dalam beberapa dekade terakhir telah bertransformasi menjadi terkomputerisasi. SIG adalah suatu alat yang mampu mengelola data mulai dari pengambilan, pengumpulan, analisis, dan visualisasi data permukaan bumi. ${ }^{22}$ SIG bekerja secara efektif dan efisien sebagai alat pemetaan karena dapat bekerja dengan banyak data sekaligus. ${ }^{23}$

Memetakan malaria dengan SIG identik dengan penggunaan GPS. Aktivitas ini telah umum dilakukan di beberapa negara untuk kasus malaria.
Pemetaan SIG diterapkan secara multidisiplin antara bidang kesehatan dan disiplin ilmu lainnya. Sebagai contoh, SIG digunakan dalam pemetaan kasus malaria dan faktor-faktor yang mempengaruhi terjadinya kasus malaria. ${ }^{24}$ Terdapat penelitian yang menggunakan koordinat GPS sebagai alat pengumpulan kasus malaria yang dikombinasikan dengan data populasi, lingkungan, dan perilaku, serta kebiasaan nyamuk vektor. Hasil penelitian tersebut berupa data kejadian malaria dan beberapa bentuk dukungan untuk pengembangan di bidang vektor pada daerah penelitian. ${ }^{24}$

Petugas kesehatan Puskesmas Kokap membutuhkan keterampilan pemetaan menggunakan SIG dan GPS untuk mengetahui pola distribusi dan untuk mendeteksi distribusi kasus malaria karena mereka bekerja di daerah endemis malaria. Pelatihan pemetaan kasus dengan GPS akan membantu puskesmas, khususnya penanggungjawab program malaria, dalam memetakan kasus, menghubungkan antara kasus malaria dengan keberadaan vektor dan tempat berkembang biak, mempelajari area yang berisiko, serta memprediksi kejadian malaria di masa depan. Hal tersebut sangat membantu dalam penentuan area prioritas intervensi penanggulangan malaria. Aplikasi tersebut juga berguna dalam pengawasan dan respon terhadap wabah atau KLB. ${ }^{5}$

\section{Kesimpulan}

Pemberdayaan petugas mikroskopis puskesmas, ahli entomologi, dan penanggungjawab program malaria di puskesmas diharapkan dapat mendukung upaya eliminasi malaria. Pelatihan menunjukkan bahwa terdapat peningkatan pengetahuan petugas puskesmas yang mengikuti pelatihan mikroskopis dan entomologis. Petugas mikroskopis memiliki akurasi baik dalam mendiagnosis Plasmodium dan petugas entomologi cukup terampil dalam mengenali perkembangbiakan larva, mengoleksi nyamuk Anopheles, serta mengenali spesies vektor malaria. Di samping itu, penanggungjawab program malaria di Puskesmas Kokap dan Dinas Kesehatan Kulon Progo diharapkan telah memiliki kemampuan pemetaan dengan pendekatan GIS. Pemberdayaan 
petugas lokal dan fasilitas pendukung berupa alat GPS dan buku panduan yang diberikan peneliti diharapkan dapat membantu meningkatkan kesadaran dan kewaspadaan puskesmas di daerah endemis malaria di Kulon Progo, terutama di Kecamatan Kokap dalam menghadapi kasus malaria yang terjadi.

\section{Ucapan terima kasih}

Tim peneliti mengucapkan terima kasih kepada instansi yang mendukung kegiatan penelitian dan pengabdian kepada masyarakat ini, yaitu Dinas Kesehatan Kabupaten Kulon Progo, Kepala Puskesmas Kokap I, Kepala Puskesmas Kokap II, Kepala Puskesmas Girimulyo II, Kepala Puskesmas Samigaluh I, dan Ketua RT 33 Desa Soko, Kecamatan Kokap. Kegiatan penelitian ini didukung oleh Lembaga Penelitian dan Pengabdian Kepada Masyarakat (LPPM) UGM yang memberikan dana hibah melalui skema Iptek bagi Masyarakat (IbM) pada tahun 2013.

\section{Daftar pustaka}

1. Kementerian Kesehatan Republik Indonesia. Indikator kesehatan Indonesia 2005-2009. Jakarta: Pusat Data dan Surveilans Epidemiologi Kementerian Kesehatan Republik Indonesia; 2010.

2. Dinas Kesehatan Kabupaten Kulon Progo. Profil kesehatan Kabupaten Kulon Progo 2011 data tahun 2010. Kulon Progo: Dinas Kesehatan Kabupaten Kulon Progo; 2011.

3. Kementerian Kesehatan Republik Indonesia. Epidemiologi malaria di Indonesia. Jakarta: Buletin Jendela Data dan Informasi Kesehatan Triwulan I; 2011.

4. Murhandarwati EEH, Fuad A, Nugraheni MDF, Sulistyawati, Wijayanti MA, Widartono BA, et al. Early malaria resurgence in pre-elimination areas in Kokap Subdistrict, Kulon Progo, Indonesia. Malar J. 2014;13:130.

5. Kementerian Kesehatan Republik Indonesia. Keputusan Menteri Kesehatan Republik Indonesia Nomor 293/Menkes/SK/IV/2009 tentang eliminasi malaria di Indonesia. Jakarta:
Kementerian Kesehatan Republik Indonesia; 2009.

6. Setjen Depkes Republik Indonesia. Petunjuk teknis standar pelayanan minimal bidang kesehatan di kabupaten/kota. Keputusan Menteri Kesehatan Republik Indonesia Nomor 828/Menkes/SK/IX/2008. Jakarta: Biro Hukum dan Organisasi; 2008.

7. Kesehatan Masyarakat. Deteksi dini kejadian luar biasa. Peran puskesmas pada kegiatan deteksi dini dan kajian epidemiologi kejadian luar biasa (KLB) [Internet]. Indonesian Public Health; 2015 [updated 2015 June 30]. Available from: http://www.indonesian-publichealth. com/2013/08/deteksi-dini-klb.html

8. Kabupaten Kulon Progo. Peraturan Bupati Kulon Progo Nomor 67 Tahun 2013 tentang eliminasi malaria di daerah. DIY: Berita Daerah Kabupaten Kulon Progo; 2013.

9. Adisasmito W. Sistem kesehatan. 2nd ed. Jakarta: PT Raja Gafindo Persada; 2014.

10. Kurniati A, Efendi F. Kajian SDM kesehatan di Indonesia. Jakarta: Salemba Medika; 2012.

11. Murhandarwati E, Fuad A, Herwanto G, Kusumasari $R$, Wijayanti $M$, Supargiyono S. Cross -check digital sebagai alternatif uji banding pemeriksaan mikroskopis malaria secara manual di Kulon Progo. Jurnal Pengabdian Kepada Masyarakat. 2018;4(1):72.

12. Tuti $S$, Worowijat. Situasi mikroskopis malaria di berbagai laboratorium daerah endemik. Bul Penelit Kesehat. 2009;12(4):432-41.

13. Tuti $S$, Dewi $R$ M, Nurhayati. Pengendalian malaria dengan peran serta masyarakat di Lampung Selatan. Bul Penelit Kesehat. 2009; Suppl:64-76.

14. Tuti S. Beberapa prinsip dasar pemantapan Kualitas (Quality Assurance/QA) petugas mikroskopis malaria. J Indonn Med Assoc. 2010;60(7):329-36.

15. Hiswani. Gambaran penyakit dan vektor malaria di Indonesia. USU Digital Library; 2004.

16. World Health Organization. Manual on practical entomology in malaria. Part II. Methods and techniques. Geneva: Division of Malaria 
and Other Parasitic Diseases, World Health Organization; 1975.

17. Service M. Medical entomology for student. 4th ed. United Kingdom: Cambridge University Press; 2008. pp. 33-49.

18. Achmadi UF. Manajemen penyakit berbasis wilayah. Jakarta: Penerbit Kompas; 2005.

19. Munif A, Imron TA M. Panduan pengamatan nyamuk vektor malaria. Jakarta: CV Sagung Seto; 2010.

20. Soedarto. Malaria: Referensi mutakhir epidemiologi global - Plasmodium - Anopheles penatalaksanaan penderita malaria. Jakarta: CV Sagung Seto; 2011.

21. Ross Z. Mapping disease: Deciphering geographics patterns from cholera to breast cancer. Ribbon. 2001;8(I):1-3.

22. Sugandi D, Sugito NT. Sistem Informasi Geografi (SIG). Jakarta: Jurusan Pendidikan Geografi, Fakultas Pendidikan IImu Pengetahuan Sosial, UPI; 2008. p. 0-47.

23. Rajagukguk J, Manalu D. Peranan Sistem Informasi Geografis (SIG) dalam pembangunan dan pengembangan daerah di era otonomi. In: Prosiding Seminar Teknologi Informasi STMIK IBBI; 2011 April 19-20; Medan. Medan: STMIK IBBI; 2011. p. 313-25.

24. Oluwafemi OA, Babatimehin OI, Oluwadare TS, Mahmud UM. Mapping malaria case event and factors of vulnerability to malaria in ileife, southwestern Nigeria: Using GIS. EJESM. 2013;6(4):365-75. 